\title{
Inconel 718 aleaziozko pieza asimetriko baten konformatzea prentsa gabe?
}

\section{Is it possible to form an asymmetric part made of Inconel 718 without using a forming press?}

\author{
Ariadna Gil Vildósola ${ }^{1}$, Adrián Rodríguez Ezquerro ${ }^{2}$, \\ Edurne Iriondo Plaza*3, Mariluz Penalva Oscoz ${ }^{4}$, Mikel Ortiz Edesa ${ }^{4}$, \\ Luis Norberto López de Lacalle Marcaide ${ }^{2-3}$ \\ ${ }^{1}$ Metal Estalki S.L. \\ ${ }^{2}$ CFAA-Fabrikazio Aeronautiko Aurreratuko Zentroa \\ ${ }^{3}$ Bilboko Ingeniaritza Eskola, UPV/EHU \\ ${ }^{4}$ Tecnalia, Industria eta garraioa
}

LABURPENA: Artikulu honek berresten du posible dela Inconel 718 aleaziozko pieza asimetriko bat prentsa gabe konformatzea. Aurkeztutako ikerketa-lanak bola bidezko leunketa hidrostatikoaren errendimendua balioztatzeko asmoa du, aurrez inkrementalki konformatutako Inconel 718 aleazio aeronautikoko piezetan. Lanaren helburua pieza aeronautikoen gainazal akaberaren optimizazioa da. Konformazio inkrementalaren eta bola-leunketaren konbinazioa balioztatzeak berrikuntza-maila handia aurkezten du eta aitzindaria da bere aplikazioan. Pieza konformatuaren gainazalaren kalitatea aztertu ondoren bola bidezko leunketa hidrostatikoa aplikatu da. Egindako emaitzek baieztatu dute proposatutako estrategiaren bideragarritasuna, zimurtasuna $\% 33$ eta $\% 70$ artean murriztea, tratatutako eremuaren arabera.

HITZ GAKOAK: xafla konformazio inkrementala, leunketa hidrostatikoa, Inconel 718, gainazal akabera eta zimurtasuna.

\begin{abstract}
This article upholds the possibility of forming an aeronautical component made of Inconel 718 sheet by means of Incremental Sheet Forming and without using a forming press. The research work presented aims to validate the operation of the hydrostatic ball burnishing as a strategy to improve the surface quality of an aeronautical component of Inconel 718, previously shaped by Asymetric Incremetal Sheet Forming (AISF). The combination of both processes, burnishing on AISF, has a very high level of innovation and is a pioneer in its application on an industrial component made of this high performance nickel-chromium alloy. The surface quality of the incrementally shaped component has been studied to subsequently apply a burnishing by means of the hydrostatic ball. The results obtained confirm the feasibility of the proposed strategy, with a reduction in roughness ranges between 20 and $65 \%$, depending on the area treated.
\end{abstract}

KEYWORDS: incremental sheet forning (ISF), hydrostatic ball burnishing, Inconel 718 , surface finishing and roughness.

\footnotetext{
* Harremanetan jartzeko / Corresponding author: Edurne Iriondo. Bilboko Ingeniaritza Eskola. Ingeniaritza Mekanikoa Saila. Rafael Moreno «Pitxitxi» Pasealekua, 3. 48013 Bilbo. - edurne.iriondo@ehu.eus - https://orcid.org/0000-0002-4552-3214.

Nola aipatu / How to cite: Gil Vildósola, Ariadna; Rodríguez Ezquerro, Adrián; Iriondo Plaza, Edurne; Penalva Oscoz, Mariluz; Ortiz Edesa, Mikel; López de Lacalle Marcaide, Luis Norberto (2019). «lnconel 718 aleaziozko pieza asimetriko baten konformatzea prentsa gabe?»; Ekaia, ale berezia 2019, 57-70. (https://doi.org/10.1387/ekaia.19902).

Jasoa: 5 ekaina, 2018; Onartua: 21 iraila, 2018.
}

ISSN 0214-9001 - eISSN 2444-3255 / (c) 2019 UPV/EHU

(c) (i) (-) Obra hau Creative Commons Atribución 4.0 Internacional-en lizentziapean dago 
Ariadna Gil, Adrián Rodríguez, Edurne Iriondo, Mariluz Penalva, Mikel Ortiz, Luis Norberto López de Lacalle

\section{SARRERA}

Lan honen helburua da bola bidezko leunketa hidrostatikoaren erabilera balioztatzea inkrementalki konformatutako piezetan, azalera-zimurtasuna murriztuz sektore aeronautikoaren eskakizunak betetzeko. Pieza gainazal osoan zehar bermatu behar da bi prozesu horiek konbinatuz.

Hegazkinen desplazamendua hegalei atxikitzen zaizkion turbinei esker lortzen da. Airea konprimatu eta errekuntzako ganberetan sartzen da, non erregaiak etengabe erretzen diren. Presio eta tenperatura altuko airea turbina batera eramaten da, partzialki zabaltzen baita konpresorea mugitzeko duen energia lortzeko. Atzeko errodamenduen karkasa (Tail Bearing Housing-TBH) presio baxuko turbina amaieran dagoen pieza estatikoa da, 1. irudian adierazten den moduan.


1. irudia. (ezk.) Atzeko errodamenduen karkasaren (TBH) kokapena, (erdian) TBH-ko baoen seinalizazioa eta (esk.) lortu nahi den bao-erdia.

Gaur egun, TBH formako egiturak forjaketa eta galdaketa prozesuak bateratuz fabrikatzen dituzte pisua murrizteko eta Inconel 718 aleazioan egiten dira. Goi mailako nikel-kromo aleazio bat da (1. taulan adierazten den bezala), ingurune korrosiboak jasateko diseinatu dena. Halaber, aparteko propietateak erakusten ditu, esate baterako, erresistentzia handia du isurpen eta hutsegite tentsioetan tenperatura altuetan. Material honen erabilera turbinen, sektore aeroespazialen, energia nuklearra sortzeko instalazioetan eta abar nagusitzen da.

1. taula. Konposizio kimikoa (masaren \%): Inconel 718.

\begin{tabular}{c|c|c|c|c|c|c|c}
\hline $\mathrm{Ni}$ & $\mathrm{Cr}$ & $\mathrm{Fe}$ & $\mathrm{Mo}$ & $\mathrm{Nb}$ & $\mathrm{Co}$ & $\mathrm{Mn}$ & $\mathrm{Cu}$ \\
\hline $50,0-55,0$ & $17,0-21,0$ & balantzea & $2,8-3,3$ & $4,75-5,5$ & 1,0 & 0,35 & $0,2-0,8$ \\
\hline $\mathrm{Al}$ & $\mathrm{Ti}$ & $\mathrm{Si}$ & $\mathrm{C}$ & $\mathrm{S}$ & $\mathrm{P}$ & $\mathrm{B}$ \\
\hline $0,65-1,15$ & 0,3 & 0,35 & 0,08 & 0,015 & 0,015 & 0,006 \\
\hline
\end{tabular}


Lan honen helburua da konformazio inkrementalaren eta bola-leunketaren konbinazioa balioztatzea. Horrela, TBH-en baoak zatietan fabrikatu ahal izango dira konformazio inkrementalaren bidez ondoren bola hidrostatiko bidezko leunketa tratamendua aplikatuz. Akabera tratamendu hau beharrezkoa da, konformazio inkrementalak piezari ematen dion gainazal akaberak ez baititu zimurdura-baldintzak betetzen.

\subsection{Xafla konformatu inkrementala}

Xafla konformatu inkrementala Incremental Sheet Forming (ISF) deitzen da ingelesez eta xaflak deformatzeko teknologia ez-konbentzional bat da. Xaflari deformazio plastiko lokalizatu eta progresiboa aplikatzen zaio puntzoi borobil baten bidez eta erreminta borobilak ibilbide jarraitua eramaten du ZK (zenbakizko kontrol) programa batek zuzenduta [1-5].

Konformazio prozesu honen lehen abantaila da xafla azpiko euskarri/ matrize gabe edo kostu baxuko matrize bat erabiliz egin daitekeela. Honek malgutasun handia eskaintzen du piezaren edozein diseinu-aldaketaren aurrean: nahikoa da erremintaren ibilbidea aldatzea eta matrize berri bat mekanizatzea, erretxinezkoa edo zurezkoa. Ohiko matrizeei lotutako diseinu, fabrikazio eta puntuan jartzeko inbertituarekin konparatuz, denbora eta kostu murrizketa garrantzitsuak lortzen dira prozesu honekin.

Hala ere, ISF prozesuak prozesu-denbora luzeak eskatzen ditu (minutudozenetatik ordu gutxi batzuetara). Horregatik, prototipoen eta pieza sorta txikien fabrikaziora egokitzen da, ohiko matrizeei lotutako kostuak eta epeak onartezinak gertatzen diren kasuetan.

Bi konfigurazio posible daude: negatiboan konformazioa (lanabesa finkoa da eta erreminta geometria konkaboa osatuz jaisten da) eta positiboan konformazioa (erremintak pieza konbexua konformatzen du markoa beherazko norabidean irristatzea eraginez).

ISFa gutxienez 3 ardatz eta konformazio erreminta lanabes gainean ezartzeko mahaia duen edozein zenbakizko kontroleko makinatan aurrera eraman daiteke. Aukeratutako makinaren ezaugarrien baldintzapean daude konformatu daitekeen geometria eta xafla lodiera maximoa. Kasu honetan erabilitako makina Gantry 5 ardatzeko motakoa da. 5 ardatzeko ATOM prototipo bat da eta honen burua TECNALIAk garatutako $20 \mathrm{kN}$-eko gehienezko esfortzu axialak jasan ahal dituena.

Konformatzeko pieza finkatzea beharrezkoa da eta horretarako lanabesa erabiliko da bere muturretatik finkatuz (2. irudia) eta zona zentrala libre utziz, erremintak pieza konformatu ahal izateko. Erremintei dagokienez, bi erreminta-mota erabil daitezke: puntzoi motakoa erabiliena eta sinpleena da, bere desabantaila nagusia xaflaren eta erremintaren arteko marruskadura altua izanik. Xaflaren gainazal-kalitateari zuzenki 
Ariadna Gil, Adrián Rodríguez, Edurne Iriondo, Mariluz Penalva, Mikel Ortiz, Luis Norberto López de Lacalle

eragiten dio eta prozesuaren indarrak areagotzen ditu. Gurpil motakoek, berriz 5 ardatzeko makina edo roboten erabilera eskatzen dute, ibilbidea konplexuagoa delarik. Azken honek aurkezten duten abantaila da erremintak jasaten duen higadura txikiagoa dela eta piezaren gainazal kalitatea hobea.

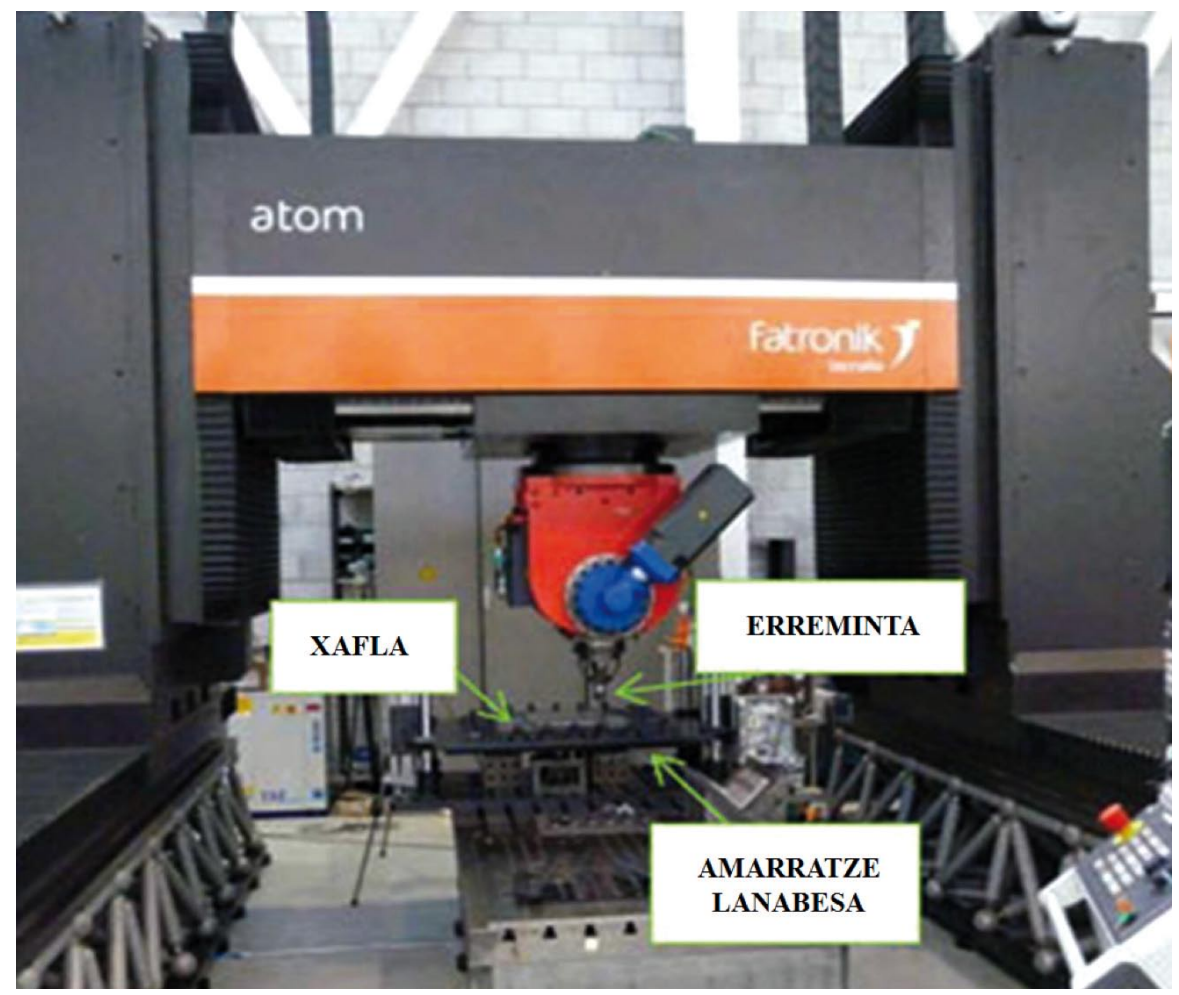

2. irudia. Tecnaliaren konformatu inkrementaleko gailua.

Prozesu hau aplikatzeko orduan beharrezkoa da lubrifikazioa izatea, erreminta eta xaflaren arteko kontaktu egokia bermatzeko, gehiegizko zarata eta erremintaren higadura azeleratua, xaflaren gainazal-kalitatearen hondatzea eta xaflaren gainberotzea ekiditeko.

\subsection{Bola bidezko leunketa hidrostatikoa}

Deformazio bidezko leunketa gainazalaren deformazio plastikoko tratamendu bat da, piezei propietate fisiko eta mekanikoak hobetzeko aplikatzen zaie $[6,7]$, aleazio mekanikoen plastikotasunari loturiko mekanismoak aprobetxatuz. Eskaintzen dituen abantaila nagusiak hauek dira: 
- Zimurtasun-murrizketa, artezketaren antzeko akabera lortuz.

- Perdoi dimentsionalen mantentzea, 0,01 milimetro azpitik.

- Gainazal-gogortasunaren igoera \% 60 arte (Brinell gogortasun eskalan), higadura erresistentzia handituz.

- Gainazalean konpresioko hondar-tentsioak garatzen ditu, piezaren bizitza-nekea luzatuz.

Bolazko leunketa hidrostatikoa mekanizazio zentro batean muntatzen den erreminta batean oinarritzen da, erremintari akoplatzen zaion bonba hidraulikoarekin batera (3. irudia) presiozko taladrinaz hornitzeko, $40 \mathrm{MPa}-\mathrm{ko}$ gehienezko presioarekin [8]. Erremintak aske biratzen duen bola esferiko bat du puntan eta hidrostatikoki bonbaren presioak eusten du. Bola leundu behar den materiala baino gogorragoa izan behar da eta normalean material zeramikazkoa edo metal gogorrekoa izan ohi da. Erreminta leundu beharreko piezaren gainazalaren gainetik pasatzerakoan, bola zimurtasun-tontorrak zapalduz doa, materiala haranen gainean zabalduz: azalera beteaz eta uniformatuz. Materialaren isurpen-tentsio hori gainazalgeruzetan gainditu ondoren ematen da [9].
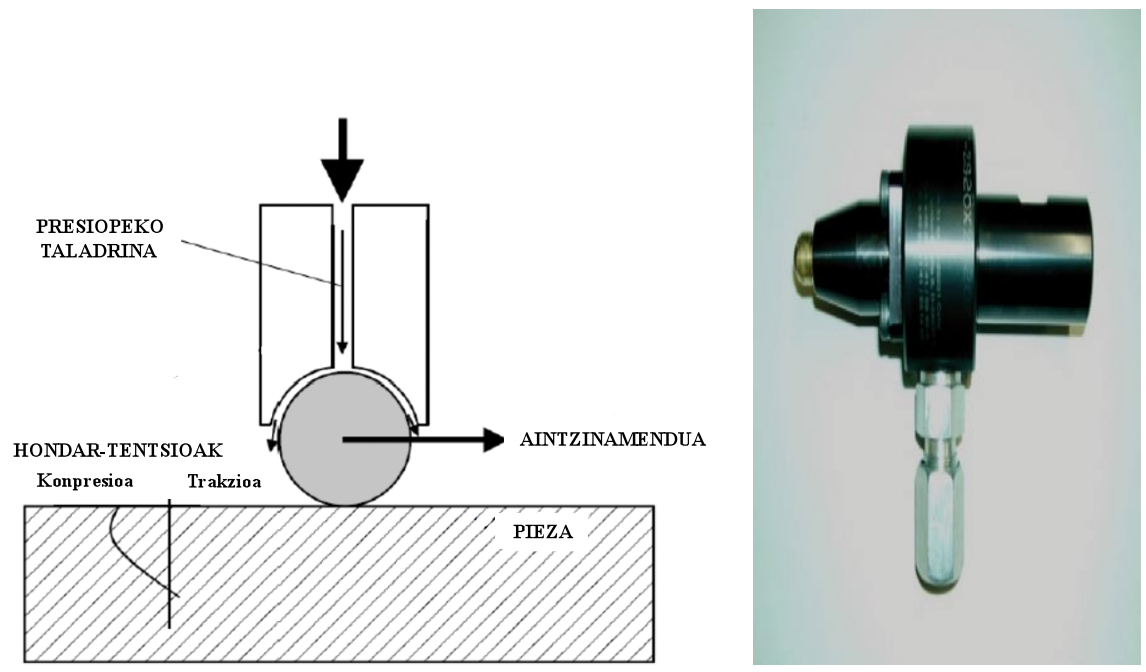

3. irudia. (Ezk.) Bola bidezko leunketa hidrostatikoaren osagaiak [10] eta (esk.) leunketa erreminta.

Erabiltzen den bolaren diametroa 3 eta $12 \mathrm{~mm}$ bitartekoa da, leundu beharreko azaleraren arabera. Bola honek, aske biratzeaz gain, erremintaren normalaren norabidean $6 \mathrm{~mm}$-ko higidura librea du.

Prozesu honen muga nagusia leunketa gainazalaren normala eta erremintaren ardatzak sortzen duten angeluan dago, honek $\pm 28^{\circ}$-koa izan behar 
Ariadna Gil, Adrián Rodríguez, Edurne Iriondo, Mariluz Penalva, Mikel Ortiz, Luis Norberto López de Lacalle

duelarik. Barruti honen barne indar normala gutxi gorabehera konstantea izango da. Ordea, barruti honetatik ateratzen bada, kalteak gerta daitezke erremintan eta piezan talkengatik eta kontaktuengatik, erremintak piezaren kontra eraginda. Pieza konplexuetan maila hau gainditu ohi da, leunketa 5 ardatzeko zenbakizko kontrol bidezko mekanizazio-zentroan eginez, erreminta honela piezaren gainazalarekiko perpendikular mantentzen ahal delarik. Prozesuaren parametroen aldaketak eragina du piezaren ezaugarrietan, piezan sortutako tentsioetan, gogortasunean eta gainazaleko akaberan. Azter daitezkeen parametrorik erabakigarrienak honako hauek dira:

- Leunketa-presioa (MPa): 5 eta $40 \mathrm{MPa}$ tartean aldatzen ahal da eta bonba-hidraulikak ezartzen du.

- Leunketa-iraganaldiaren zabalera: zenbat eta iraganaldi zabalera txikiagoa izan, gainazal-akabera hobea izango du. Ordea, prozesuan erabili beharreko denbora luzeagoa izango da.

- Leunketaren norabidea, piezak aurrez konformazio inkrementalean erremintak eramandako norabidearekiko kontsideratzen da: perpendikularra, paraleloa edo angelua duena.

\section{GARAPEN ESPERIMENTALA}

Hemen aurkezten dira aztertutako piezak bete behar dituen diseinu baldintzak, balidazio esperimentalean aurrera eramateko jarraibideak, hain zuzen.

\subsection{Diseinu eskakizunak}

Lan honen helburua da TBH piezaren baoak konformazio inkrementalaren bidez fabrikatzea. Horretarako bao-erdiak konformatu dira inkrementalki, ondoren ur-zurrusta bidez moztu dira neurri doietan eta beren artean soldatu dira (1. irudia). Behin baoak prest daudenean, hauek eraztunari soldatzen zaizkio TBHa osatzeko.

\subsubsection{Gainazal akabera}

Piezaren konformazioa piezaren bista-aurpegiaren kontrako aurpegian ematen da, bista-aurpegian sortuko den zimurtasuna minimizatu nahian. Neurri hau hartuta ere, ez da betetzen bezeroak mugatutako 3,2 $\mu$ m-tako zimurtasun onargarria (4. irudia). Piezaren bista-aurpegian marra batzuk sortzen dira eta hauek konformazio-iraganaldiaren zabalerekin bat datoz. Nahiz eta bukaerako iraganaldi berezi bat aplikatu, ezaguna da piezaren gainazalaren zimurdura prozesua martxan hasten duen erremintaren lehen iraganaldiak inprimatzen duela. Egiaztatzen da bukaera iraganaldia ez dela gai hasieratik izango den zimurtasuna hobetzeko piezaren bista-aurpegian. 


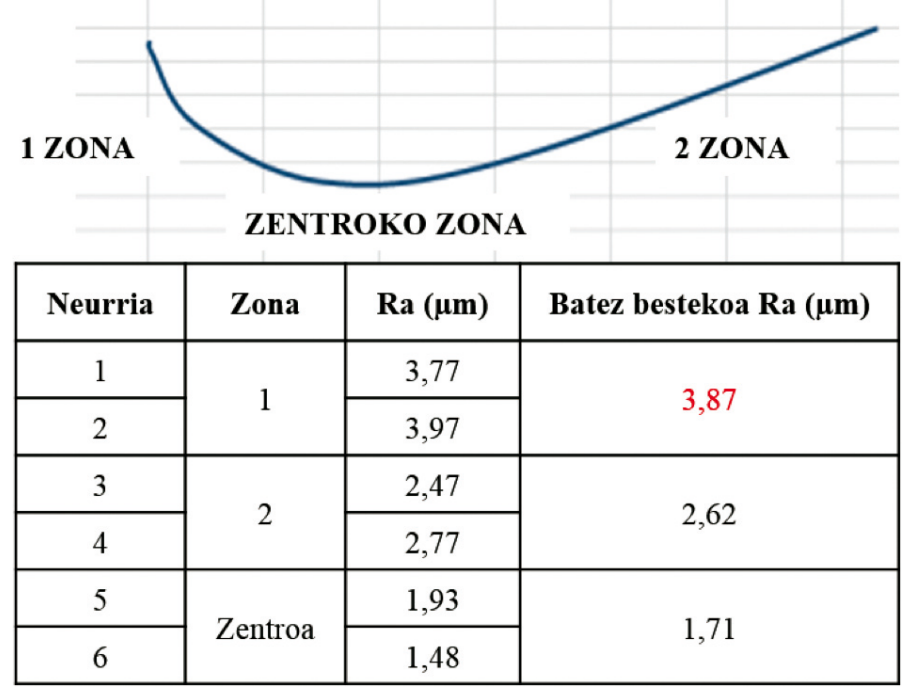

4. irudia. Konformatutako piezaren gainazal akaberaren balioak.

Horregatik lan honetan, gainazaleko akabera da hobetzeko alderdi garrantzitsuena eta horregatik erabaki zen leunketa hidrostatikoa erabiltzea bera hobetzeko. Gainazaleko zimurtasuna Leica DCM-a 3-D perfil-metro eta mikroskopio optikoarekin neurtuko da. Gauss-en iragazkia aukeratzen da eta mozketa luzera (Lc) edo Cutoff, 2,5 mm-koa izango da.

Mozketa-luzera da uhinduraren eta zimurtasunaren artean bereizteko erabiltzen den distantzia. Desbideratzearen tartea handiagoa edo mozketaluzeraren berdina bada, uhindura izango da eta ordea, distantzia txikiagoa bada, zimurtasuna izango da, aztertu nahi den faktorea azken hori izanez. Uhinduraren ezabapena egin ahal izateko, profilaren neurriaren seinalea iragaztea beharrezkoa da: kasu honetan Gauss-en iragazkia erabiliko da, zeina modelo matematiko batean oinarritzen baita.

\subsubsection{Xafla lodiera}

Piezaren lodieraren uniformetasuna mantentzea kontuan hartzeko beste alderdi bat da. Horregatik, leunketa hidrostatikoaren aplikazioaren ondoren, egiaztatu behar da piezak lodiera uniformea mantentzen jarraitzen duela, eta eraginpean egonez gero, eskatutako perdoi barruan izan dadila, xaflaren hasierako lodieraren \% 10eko murrizketa maximoa izanik onargarria. 
Ariadna Gil, Adrián Rodríguez, Edurne Iriondo, Mariluz Penalva, Mikel Ortiz, Luis Norberto López de Lacalle

\subsection{Balidazio esperimentala}

\subsubsection{Bola bidezko leunketa sistemaren prestaketa}

Konformazio inkrementalez egindako piezan parametro ezberdinak aztertu dira. Hauexek dira entsegu honetan lortu nahi ziren helburuak:

- Inconel 718an egindako piezaren zimurdura hobetzea leunketa ondoren.

- Hauexek dira entsegu honetan lortu nahi ziren helburuak, konformazio inkrementalaren ibilbidearen norabidearekiko.

- Leunketarako parametroen leiho optimoa ezartzea.

- Molde baten erabilera balioztatzea piezaren deformazioa saihesteko leunketa fasean.

Pieza gainean leunketa hidrostatikoa aplikatu aurretik, molde bat prestatzea beharrezkoa da moldeak leunketa-esfortzuak jasan ditzan, pieza deformatu baitaiteke oinarri baten ezean. Moldea egiteko, hotzean kapsulatzeko erretxina erabiltzea erabakitzen da. Erretxina katalizatzailearekin nahastu, pieza barrura isuri eta lehortzen uzten da, moldea lortuz.

Behin leunketarako parametroak eta estrategia zehaztu direnean, leunketa aurrez inkrementalki konformatutako piezaren gainazalean aplikatzen da.

Aurretiko entseguetan lortutako parametro optimoak:

- Bonbaren presioa: $10 \mathrm{MPa}$.

- Iraganaldien arteko distantzia: $0,1 \mathrm{~mm}$.

- Abiadura: $7.000 \mathrm{~mm} / \mathrm{min}$.

- Leunketa-norabidea: konformatu inkrementalean aplikatutako ibilbidearen norabideari perpendikularra.

Nahiz eta gainazal-akabera emaitzarik onenak $0,05 \mathrm{~mm}$ zabalerako iraganaldiarekin lortu diren, ikusten da $0,1 \mathrm{~mm}$-ko iraganaldi zabalerarekin, emaitzek ez dutela ezberdintasun handirik $0,05 \mathrm{~mm}$ zabalerakoekin alderatuz. Gainera, kontuan izan behar da prozesu denbora ia bikoitza dela $0,05 \mathrm{~mm}$-ko zabalera aplikatzen bada; gainera, gainazal-zimurdura eta prozesu-denboraren oreka bilatu nahian, $0,1 \mathrm{~mm}$-ko iraganaldi zabalera aplikatzea erabakitzen da.

Leunketa hidrostatikoa aplikatzeko orduan, abiadura ez da kontsideratzen zimurduran eragina duen parametro bat eta $7.000 \mathrm{~mm} / \mathrm{min}$-ko abiadura kontserbakor bat aukeratzen da.

Leunketa piezaren gainazal osoan zehar aplikatzeko eta piezaren normalaren eta erremintaren ardatzaren arteko angelua $\pm 28^{\circ}$-ko barrutian mantendu behar bada, 5 ardatzeko mekanizazio zentro bat beharko litza- 
teke. Kasu honetan, 3 ardatzeko makina erabili ahal izateko, leunketa-gainazala mugatu da eta hau 5. irudian adierazten da.

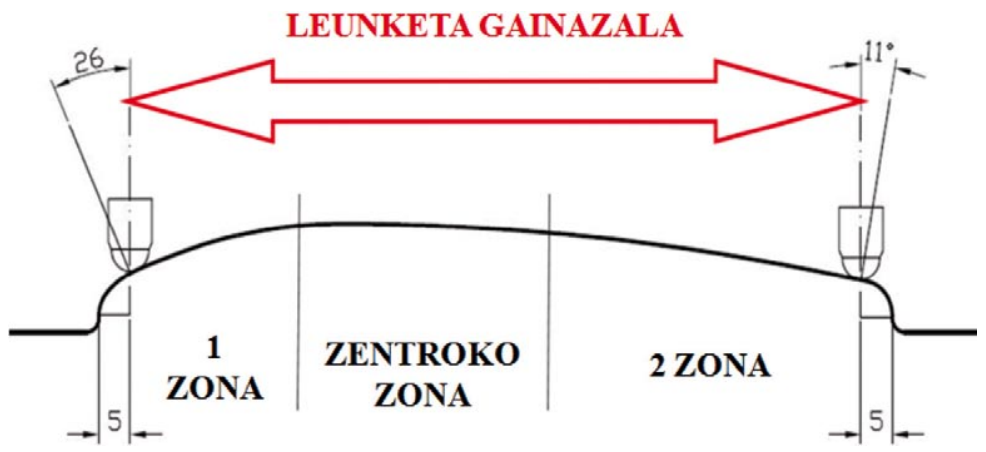

5. irudia. Leunketa aplikatuko den gainazalaren mugak eta zonen banaketa.

Leunketa aplikatzeko iraupena piezaren gainazal osoan zehar ordu betekoa da. Behin prozesua perfekzionatuz joan ala eta erabilitako mekanizazio zentroaren arabera, denbora hau murriztu ahal izango da. Leunketa aplikatutako gainazalaren azalera $350 \times 150 \mathrm{~mm}$-koa da.

\section{EMAITZAK}

Ondoren balidazio esperimentalean zehar lortutako emaitzak aurkezten dira.

\subsection{Gainazal zimurtasuna}

Leica DCM 3-D perfil-metro eta mikroskopio optikoarekin lortutako emaitzen azterketari ekiten zaio. Neurriak 2,5 mm-ko mozketa-luzera batekin egingo dira. Piezaren konformazio prozesuagatik, honek gainazalean zimurtasun balio desberdinak ditu X ardatzean zehar. Y ardatzean zehar gainera, gainazala ez da uniformea eta zentroan ahurtasun-maila bat erakusten du.

Horregatik, leunketa-azalera sei zonatan banatzen da, neurriak zona bakoitzean hartuz. Leunketa konformatu inkrementalaren ibilbideari perpendikularra egiten denez, neurriak bi zentzuetan egingo dira:

- X ardatzean: leunketaren noranzkoan eta norabide honetan neurtzen da konformatu inkrementalak sortutako gainazalaren zimurdura.

- Y ardatzean: konformatu inkrementalaren noranzkoa eta norabide honetan leunketak sortutako gainazal zimurtasuna neurtzen dira. 


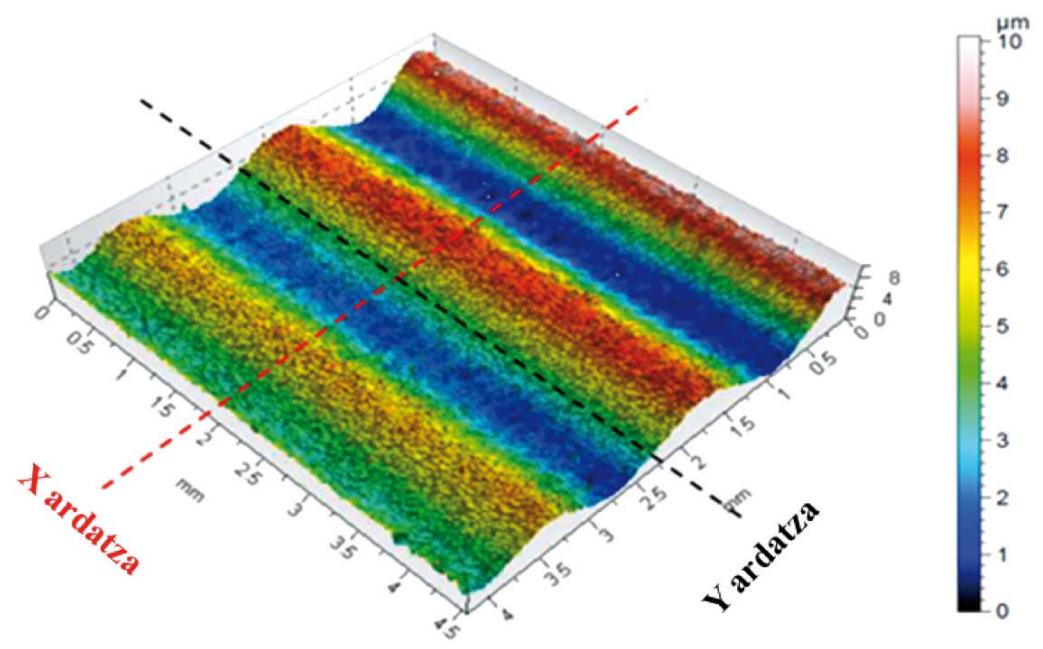

6. irudia. Leunketa aplikatuko gainazalaren topografia.

7. irudiak zimurtasunaren neurketen emaitzak erakusten ditu $\mathrm{X}$ ardatzean eta honek izan duen eboluzioa leunketa aplikatu aurretik eta ondoren. Lan honen aurretik beste azterketa batzuk egin dira prozesuaren sendotasuna neurtzeko, eta bertan desbideratzea \% 5en azpitik dagoela aurkitu da. Ondorio honek prozesua sendoa eta errepikakorra dela azpimarratzen du, eta horregatik, lan honetan, bi zimurtasun neurketaren batez besteko emaitzetatik bakarrik ondorioztatu da leunketaren eraginaren joera. Prozesuaren mugak ezagutzeko, kondizio ezberdinetako gutxienezko 5 entsegu aurrera eraman beharko lirateke.

7. irudian $\mathrm{R}_{\mathrm{a}}$-ren batez besteko balioen konparaziozko taula erakusten da eta zimurtasun orokorraren murriztapena dagoela ikusten da leunketa ematerakoan. Gainazaleko akaberaren bilakaera xaflako zonaren arabera aldatzen da, murriztapen txikiena zona zentralean izanez, \% 33ko murrizketarekin; maximoa berriz 1 zonan gertatzen da, $\%$ 70eko jaitsierarekin. 


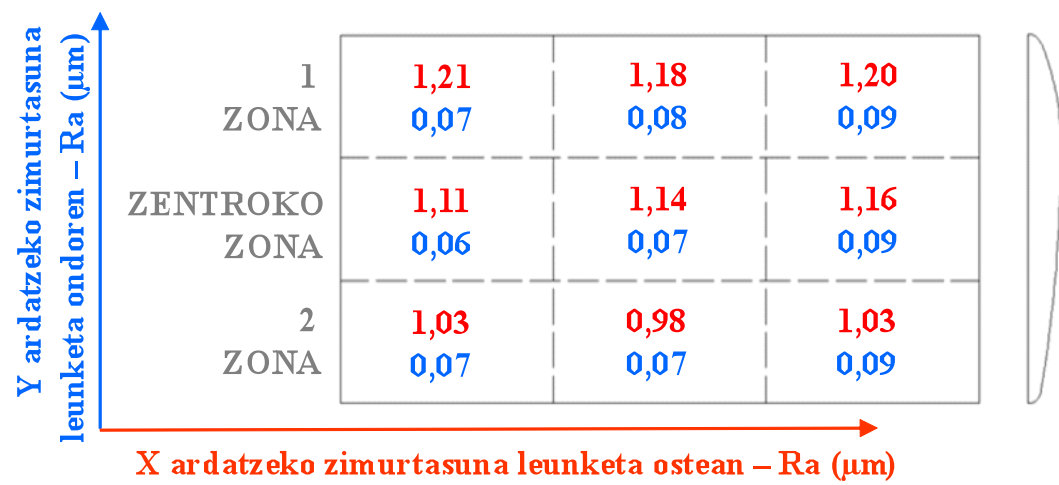

\begin{tabular}{|l|c|c|c|}
\hline \multicolumn{1}{|c|}{ Zona } & $\mathbf{R}_{\mathbf{a}}$ ISF $(\mathbf{X})$ & $\mathbf{R}_{\mathbf{a}}$ ISF + Leunketa (X) & Murrizketa \\
\hline 1 & 3,87 & 1,19 & $\% 70$ \\
\hline Zentroa & 1,71 & 1,13 & $\% 33$ \\
\hline 2 & 2,62 & 1,01 & $\% 60$ \\
\hline
\end{tabular}

7. irudia. (Goian) Gainazalaren zimurtasun baloreak zona bakoitzean eta (behean) batez besteko $\mathrm{R}_{\mathrm{a}}$-ren balioak .

\subsection{Xaflaren lodiera}

Piezaren lodiera leundutako azalera guztian zehar neurtzeko, 50 neurri egingo dira gainazal guztian zehar (8. irudian) uniformeki banatutako neurrietan. $25 \mathrm{~mm}$-ko distantzia dago 8. irudian markaturiko zutabe eta lerro denen artean.

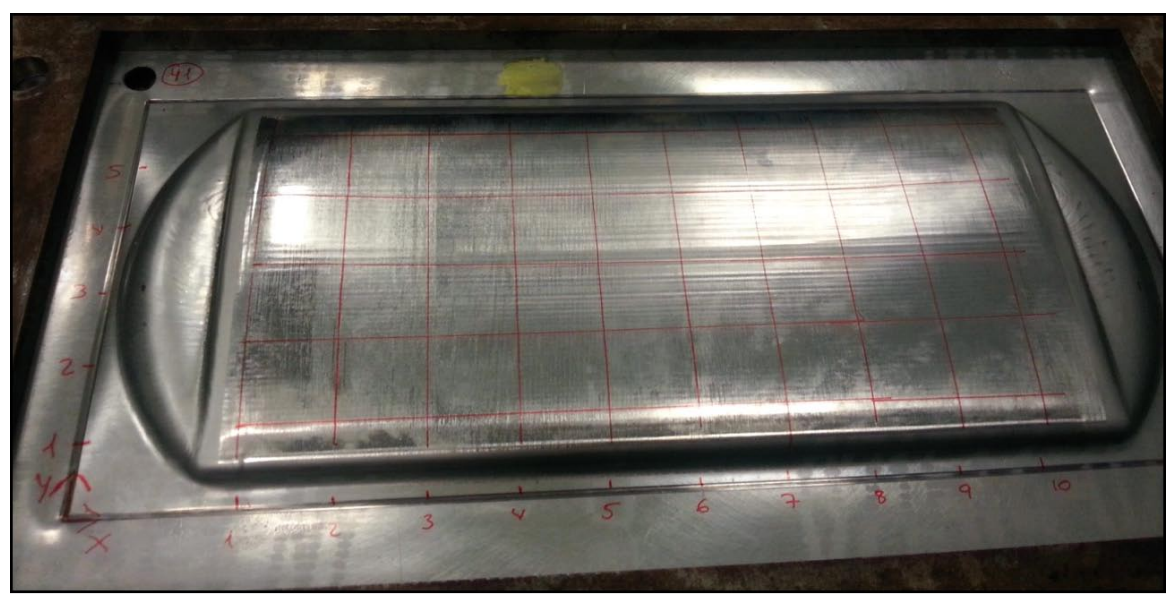

8. irudia. Pieza markatu eta erreferentziekin bere neurketarako. 
Ariadna Gil, Adrián Rodríguez, Edurne Iriondo, Mariluz Penalva, Mikel Ortiz, Luis Norberto López de Lacalle

Behin neurketak egiteko banaketa definituta izanda, neurketarekin jarraitzeko plano hau piezako azalerara zeharkatzeari ekiten zaio, 2. taulan agertzen diren balioak lortuz. Aurretiko entsegu batzuk garatu dira lan hau martxan jarri baino lehen eta bertan xaflaren lodiera konformazio inkrementalaren ondoren eta leunketa ostean neurtu da. Leunketaren ondoren xaflaren lodiera gehienez \% 1 mehetu da eta ehuneko hau oso baxua denez, lan esperimental honetan leunketa honako lodiera hauek neurtu dira bakarrik, leunketa aplikatu zaion gainazalak sektorean \% 10eko lodiera murrizketaren muga gainditzen duen ala ez ziurtatzeko.

2. taula. Konformatutako piezaren lodiera neurriak 50 puntutan zehar.

\begin{tabular}{cccccccccccc}
\hline \multicolumn{10}{c}{ Piezaren lodiera neurketa leunketa ondoren $(\mathrm{mm})$} \\
\hline & 1 & 2 & 3 & 4 & 5 & 6 & 7 & 8 & 9 & 10 \\
\hline 5 & 0,91 & 0,98 & 0,98 & 0,98 & 0,98 & 0,98 & 0,98 & 0,98 & 0,97 & 0,96 \\
4 & 0,94 & 0,97 & 0,97 & 0,98 & 0,98 & 0,98 & 0,98 & 0,98 & 0,96 & 0,96 \\
3 & 0,93 & 0,96 & 0,97 & 0,98 & 0,98 & 0,98 & 0,98 & 0,98 & 0,96 & 0,96 \\
2 & 0,96 & 0,99 & 0,99 & 0,99 & 0,99 & 0,99 & 0,99 & 0,99 & 0,99 & 0,98 \\
1 & 0,98 & 0,99 & 0,99 & 0,99 & 0,99 & 0,99 & 0,99 & 0,99 & 0,99 & 0,99 \\
\hline
\end{tabular}

Neurketen balio guztiak $1 \mathrm{~mm}$ baino txikiagoak direla ikusten da. Balio hau arrazoizkoa da, konformazioa egiteko erabiltzen den hasierako xafla $1 \mathrm{~mm}$-koa denez, konformazio inkrementala egiterakoan xaflaren azalera handitu egiten da, lodiera murriztu behar delarik. Jasandako xaflaren mehartzea onargarria da, lodiera minimoa $(0,91 \mathrm{~mm})$ aurkezten duen neurketako puntuak mugatutako \% 10 ez duelarik gainditzen.

\section{ONDORIOAK}

Behin ikerketa-lana bukatuta, ondorioztatzen da ezen, estrategia bezala, osagarri eragingarria dela leunketa hidrostatikoa erabiltzea konformatu inkrementalaren bidez egindako piezen gainazaleko akabera optimizatzeko. Lan honetan lortu nahi den azpihelburua prozesuaren joera definitzea da, piezen gainazalean leunketa hidrostatikoa aplikatzeko balioen hurbilketa bat egitea. Balio hauekin honako emaitza hauek lortu dira:

- Leunketa denbora gehiengoa mugatutako azalerarentzat: ordu 1.

- Batez besteko gainazal zimurtasuna: $\mathrm{R}_{\mathrm{a}}=1,14 \mu \mathrm{m}, \% 33$ (piezaren erdialdean) eta $\% 70$ (piezaren 1 zonan) artean murrizten da leunketa gabeko gainazalekin konparatuz eta balio muga onargarriaren $(3,2 \mu \mathrm{m})$ azpitik dago.

- Piezaren batez besteko lodiera: 0,98 $\mathrm{mm}$ (tolerantzien barnean). 
Iraganaldiaren zabaleraren eta presioaren arteko konbinazioaren eragina gainazal zimurtasunean zuzena da: zimurtasun baxuagoa gertatzen da iraganaldi estuagoa eta presio altuagoarekin. Inkrementalki konformatutako aplikatzeko leunketa presioa, $1 \mathrm{~mm}$-ko lodierako xaflarentzat, $15 \mathrm{MPa}$ izan behar da gehienez. Presioak 15 MPa gainditu ezkero, deformazioak gainazalean baino sakonago heltzeko arriskua ematen da. Lan honen aurretik garatutako azterketa baten ondorioa izan zen eta aleazio berdineko konformatu gabeko xafla lau batean aplikatu zen leunketa. Kasu honetan 9. irudian adierazten den bezala, laukizuzen orlegiaren barruan dagoen azaleran $10 \mathrm{MPa}-k o$ leunketa aplikatu zen eta beherago agertzen diren kasuetan 15 eta $20 \mathrm{MPa}$. Argi ikus daiteke $15 \mathrm{MPa}-\mathrm{ko}$ presioarekin leunketak sortutako deformazioa gainazala baino sakonago heltzen dela.

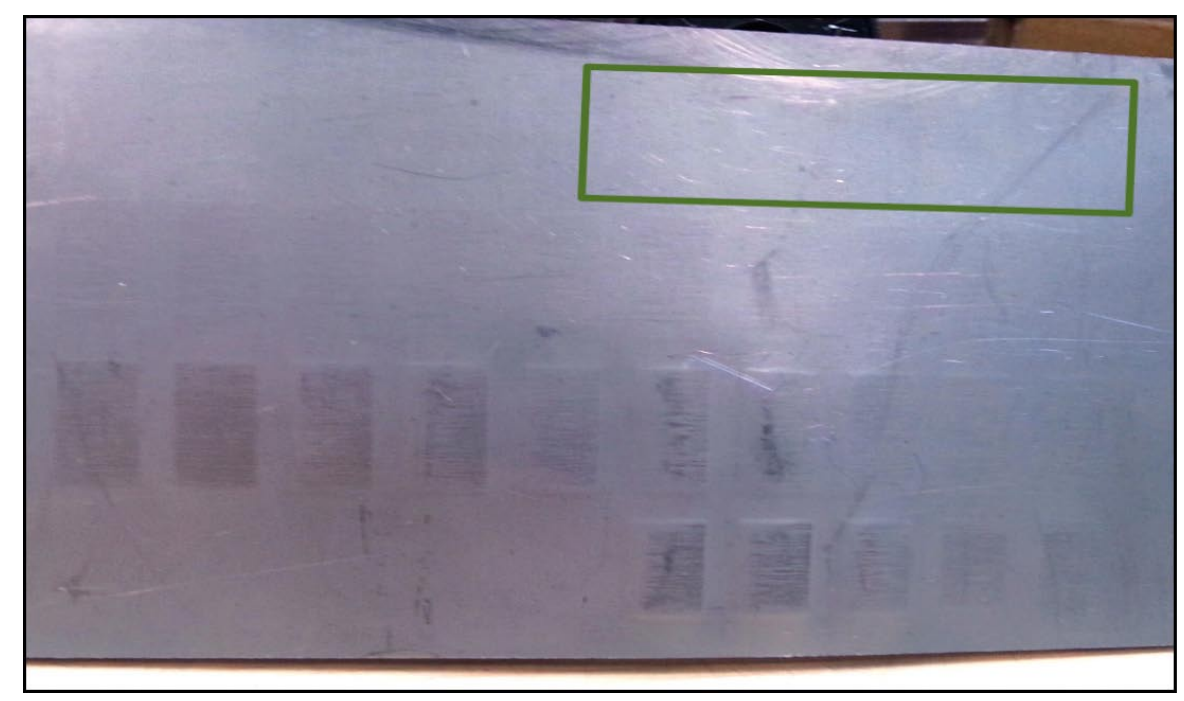

9. irudia. Leunketa presioa aukeratzeko aurretiko azterketaren emaitzak.

Leunketa-ibilbideak konformatu inkrementalaren errealizazio ibilbideari perpendikularra izan behar du, gainazaleko zimurtasuna gutxitu dezan. Gainazal konplexuko leunketa zatika egin behar den kasuan, zona desberdinak, gainjartzerik gabe, hots, elkartuz egin behar dira ibilbideak aurreko zonakoari jarraitu ahal izateko.

Lortutako emaitzek egiaztatzen dute xaflaren lodierak ez duela jasaten leunketa hidrostatikoaren eraginik bere gainazalean, eta prozesuaren ondoren neurtutako lodierak eskatutako espezifikazioen barruan sartzen dira. Molde bat piezaren behealdean kokatu behar da, leunketaren indarrak jasateko eta piezak gainazalean deformazio handiagoak sufritzea saihesteko. 
Ariadna Gil, Adrián Rodríguez, Edurne Iriondo, Mariluz Penalva, Mikel Ortiz, Luis Norberto López de Lacalle

Bukatzeko, beharrezko(tzat) jotzen da etorkizunera begira leunketak piezaren hondar-tentsioetan duen eragina aztertzea, lan honetan alderdi horri heldu ez zaion arren.

\section{BIBLIOGRAFIA}

[1] RUBIO A., PENALVA M., GRANADOS S., RIVERO A. eta GOIOGANA M. «Methodology to identify the suitability of new materials for Asymmetric Incremental Sheet Forming». IDDRG 2011 Confernce Proceedings, Bilbao.

[2] ORTIZ M., PENALVA M.L., PUERTO M.J., HOMOLA P. eta KAFKA V. «Hot Single Point Incremental Forming of Ti-6Al-4V Alloy». Key Engineering Materials 611-612, 1079-1087.

[3] DUflou, J. R., CALlEBAUT, B., VERBERT, J. eta DE BAERDEMAEKER, H. «Laser Assisted Incremental Forming: Formability and Accuracy Improvement». CIRP Annals - Manufacturing Technology, 56, 273276.

[4] TALEB ARAGHI, B., MANCO, G.L., BAMBACH, M. eta HIRT, G. «Investigation into a new hybrid forming process: Incremental sheet forming combined with stretch forming». CIRP Annals-Manufacturing Technology, 58, 225-228.

[5] LU, B. «Mechanism investigation of friction-related effects in single point incremental forming using a developed oblique roller-ball tool». International Journal of Machine Tools and Manufacture, 85, 14-29.

[6] LOPEZ DE LACALLE L. N., LAMIKIZ A., MUÑOA J. eta SÁNCHEZ, J.A., «Quality improvement of ball-end milled sculptured surfaces by ball burnishing». International Journal of Machine Tools \& Manufacture, 45, 1659-1668.

[7] LOPEZ DE LACALLE L. N., LAMIKIZ A., SÁNCHEZ, J.A. eta ARANA, J. L. «The effect of ball burnishing on heat-treated steel and Inconel 718 milled surfaces». International Journal of Advanced Manufacturing Technology, 123, 292-302.

[8] RODRÍGUEZ, A., LÓPEZ DE LACALLE, L.N., CELAYA, A., FERNÁNDEZ, A. eta UGALDE, U.J. «Aplicación del bruñido con bola para el acabado de superficies complejas en máquinas multieje». Departamento de Ingeniería Mecánica, Universidad del País Vasco. 2010.

[9] AVILES, R., ALBIZURI, J., RODRIGUEZ, A. eta LOPEZ DE LACALLE, L.N. «Influence of low-plasticity ball burnishing on the high-cycle fatigue strength of medium carbon AISI 1045 steel». International Journal of Fatigue, 55, 230-244.

[10] PREVÉY, P. S. eta CAMMETT, J. «Low cost corrosion damage mitigation and improved fatigue performance of low plasticity burnished 7075-T6». Journal of Materials Engineering Performance, 10, 548-555. 